\title{
Cross-sectional survey of flavored cigarette use among adult smokers in Singapore
}

\author{
Yvette van der Eijk', Xian Yi Ng${ }^{1}$, Jeong Kyu Lee
}

\begin{abstract}
INTRODUCTION Singapore, a city-state with a multi-ethnic Asian population, has one of the world's largest market shares for cigarettes with added flavors, such as menthol and fruit, which increase the appeal of smoking. Little is known on the sociodemographic or smoking-related traits associated with flavored cigarette use in the Asian context.

METHODS A cross-sectional survey was conducted in January-March 2020 of 1123 Singaporean adult (aged 21-69 years) current smokers using a self-completed online or postal questionnaire. We used descriptive statistics and bivariate analyses to compare the answers of flavored and non-flavored cigarette users and fitted a multivariate logistic regression model to identify correlates of flavored cigarette use.

RESULTS Of the respondents, $85.2 \%$ reported ever use and $52.7 \%$ of respondents with a regular brand reported current use of flavored cigarettes. Older age 40-49 years $(\mathrm{AOR}=0.63)$ age $\geq 50$ years $(\mathrm{AOR}=0.60)$, Indian ethnicity $(\mathrm{AOR}=0.39)$, and a moderate $(\mathrm{AOR}=0.57)$ or high $(\mathrm{AOR}=0.34)$ dependence level were correlated with non-flavored cigarette use, while female gender $(\mathrm{AOR}=2.53)$ and a later initiation age $(16-20$ years: $A O R=1.72$; age $\geq 21$ years: $A O R=2.19)$ were correlated with flavored cigarette use.

COnCLUSIOns Consistent with findings from other countries, flavored cigarette use in Singapore is associated with being younger in age, female, of a certain ethnicity (Malay or Chinese), and having a lower nicotine dependence level.
\end{abstract}

\author{
AFFILIATION \\ 1 Saw Swee Hock School \\ of Public Health, National \\ University of Singapore, \\ Singapore

\section{CORRESPONDENCE TO} \\ Yvette van der Eijk. Saw \\ Swee Hock School of Public \\ Health, National University \\ of Singapore, MD1 Tahir \\ Foundation Building, 12 \\ Science Drive 2 \#09-01C, \\ Singapore, 117549, Singapore. \\ E-mail: yvette.eijk@nus. \\ edu.sg
}

\section{KEYWORDS}

survey, menthol, Asia, Singapore, flavors

Received: 4 February 2021 Revised: 24 March 2021 Accepted: 31 March 2021

\section{INTRODUCTION}

Flavored cigarettes contain additional characterizing flavors such as menthol, mint, fruit or sweets. These flavors may be added to the tobacco leaf or incorporated into cigarettes in diverse forms such as scent infusions, surface coatings, threads, granules, microcapsules, or crushable capsules embedded in the filter. The last form, sold in what are commonly termed 'capsule cigarettes', provide an on-demand flavor which enables the user to selectively add one or more flavors to the cigarette. While flavored cigarettes have been on global markets, including Singapore's, since at least the $1970 \mathrm{~s}^{1}$, capsule cigarettes are a more recent development ${ }^{2}$, launched in Singapore in $2010^{1}$.
Tobacco flavors including menthol have become increasingly regulated with bans in Brazil, Ethiopia, Uganda, Senegal, Mauritania, Turkey, the European Union, Canada, and parts of the United States ${ }^{3,4}$. Tobacco flavor bans came in response to evidence which consistently shows that tobacco flavors, especially menthol, encourage smoking initiation ${ }^{5-10}$, increase the addictiveness of cigarettes ${ }^{11,12}$, and mislead people into thinking cigarettes are less harmful ${ }^{13-16}$. More recently, evidence from numerous countries has also illustrated the popularity of capsule cigarettes among young people owing to their novelty appeal, youthful designs, and wide variety of flavors ${ }^{17-23}$.

Singapore is a developed city-state in South-East 
Asia with a multi-ethnic (predominantly Chinese, Malay and Indian) Asian population. Although Singapore has a comprehensive and well-established tobacco control policy dating back to $1970^{24}$, Singapore has no regulations on tobacco flavors. As of 2018, Singapore's flavored cigarette market share was one of the largest in the world, with cigarette market shares of $48 \%$ for menthol (non-capsule) cigarettes and $3 \%$ for capsule cigarettes ${ }^{25}$. Singapore's menthol market grew rapidly in the 1980s and 1990s as a result of tobacco industry efforts to target young people with menthol cigarettes amidst Singapore's strict tobacco advertising and promotions ban ${ }^{1}$. Since the mid 2000s, Singapore's menthol market share has remained stable at over $40 \%$ while Singapore's capsule cigarette market, although still small, started growing rapidly in the mid 2010s and is expected to grow further into the $2020 \mathrm{~s}^{25}$.

Surveys of flavored cigarette use in the European Union $^{26}$, Poland ${ }^{27}$, United States ${ }^{28,29}$, and Chile ${ }^{30}$, have found that smokers who use flavored cigarettes are more likely to be younger in age ${ }^{26-30}$, female f6-28,30 $^{26}$ an ethnic minority ${ }^{28}$, smoking fewer cigarettes per day $^{26}$, and more likely to perceive some cigarettes as less harmful than others ${ }^{27}$. However, little is known on the sociodemographic or smoking-related characteristics associated with flavored cigarette use in Singapore or the Asian context. The goal of this study was to identify sociodemographic and smokingrelated traits associated with flavored cigarette use in Singapore.

\section{METHODS}

\section{Study design and population}

We used cross-sectional data from 1123 adult (aged 21-69 years) current smokers who were a Singapore Citizen or Permanent Resident (PR) at the time of survey. Following the Centers for Disease Control and Prevention definition ${ }^{31}$, we defined 'current smoker' as a person who has smoked at least 100 cigarettes in their lifetime and was smoking cigarettes on a daily or non-daily basis at the time of the survey. Data were provided in a self-completed online or postal survey, which included questions on sociodemographic characteristics, current smoking, smoking at the time of initiation, use of flavored cigarettes, and perceptions of different flavor variants.

We recruited survey participants in January-March
2020 from the 2019 Singapore Smokers' Survey (SSS) project. All SSS participants were adults, Singapore Citizens or PR, and current smokers who had agreed to be re-contacted for follow-up research. They had been recruited into the SSS from existing cohort studies: 1) the Singapore Population Health Studies (SPHS) cohort first follow-up study and Multi-Ethnic Cohort Phase 3 study; 2) the SPHS Online Panel; and 3 ) the National Population Health Survey 2016/2017, with further recruitment in designated smoking areas in public places, through personal contacts, and distribution of recruitment flyers.

We invited eligible participants (adult, Singapore Citizen/PR, current smoker) to participate in the survey by phone call after which they were either emailed a link to complete the questionnaire online or sent a hard copy of the questionnaire to their postal address. To increase the survey response rate, a member of the research team made a follow-up call to those who did not respond to the invitation within two weeks.

Questionnaires, as well as the participant information sheet and informed consent form shown prior to the survey, were available in English and Mandarin Chinese, the two most widely spoken languages in Singapore. The online surveys were hosted on Verint's MySurvey, from which data were electronically imported into Microsoft Excel. Data from the postal surveys were entered manually into Excel. Each participant was reimbursed with a $\$ 5$ supermarket voucher upon completion of the survey.

\section{Measurements}

\section{Flavored cigarette use at time of survey}

This was assessed with three questions. First, participants were asked: 'is there a certain brand or variant of cigarette you prefer over others?' with response 'yes/no'. Those who selected 'yes' were then asked the open-ended question 'what is the full name of your preferred brand and variant of cigarette?' and a multiple choice question 'how would you describe the flavor of that brand?' with the choice to select any of the options: 1) regular or full (tobacco) flavor; 2) light or mild; 3) menthol or mint flavored; 4) clove flavored (kretek); 5) fruit or candy flavored; and 6) flavor capsule. We grouped participants into one of two flavor categories (flavored, non-flavored) and one of five flavor subcategories (menthol, kretek, capsule, 
regular, light) accordingly (Table 1). Coding accuracy was checked against the open-ended answers and amended where necessary. A total of 861 participants (76.7\% of all participants) were categorized as flavored $(n=454)$ and non-flavored $(n=407)$ current users. The remainder either indicated they did not have a preferred brand or gave inconsistent answers which could not be coded.

\section{Flavored cigarette use at time of initiation}

We assessed this with three retrospective questions. First, participants were asked: "when you started smoking cigarettes, was there a certain brand or variant of cigarette you preferred over others?' with response 'yes/no'. Those who selected 'yes' were then asked the open-ended question 'what was the full name of that brand and variant of cigarette?' and a multiple choice question 'how would you describe the flavor of that brand?' with the choice to select any of the options: 1) regular or full (tobacco) flavor; 2) light or mild; 3) menthol or mint flavored; 4) clove flavored (kretek); 5 ) fruit or candy flavored; and 6) flavor capsule. We coded flavor categories and subcategories according

Table 1. Categories and subcategories for flavor preference

\begin{tabular}{|c|c|c|c|}
\hline $\begin{array}{l}\text { Flavor } \\
\text { category }\end{array}$ & $\begin{array}{l}\text { Flavor } \\
\text { subcategory }\end{array}$ & $\begin{array}{l}\text { Description of } \\
\text { subcategory }\end{array}$ & $\begin{array}{l}\text { Code } \\
\text { description }\end{array}$ \\
\hline \multirow[t]{3}{*}{ Flavored } & Menthol & $\begin{array}{l}\text { Contains menthol/ } \\
\text { mint, may also } \\
\text { contain other flavors } \\
\text { such as fruit or } \\
\text { candy. Does not } \\
\text { contain a crushable } \\
\text { flavor capsule. }\end{array}$ & $\begin{array}{l}\text { If (3) or (5), } \\
\text { and not (6) }\end{array}$ \\
\hline & Kretek & $\begin{array}{l}\text { Clove-flavored } \\
\text { Indonesian kretek, } \\
\text { may or may not } \\
\text { contain menthol. }\end{array}$ & If (4) \\
\hline & Capsule & $\begin{array}{l}\text { Contains a crushable } \\
\text { flavor capsule. }\end{array}$ & If (6) \\
\hline \multirow[t]{2}{*}{ Non-flavored } & Regular & $\begin{array}{l}\text { Does not contain } \\
\text { added flavors and } \\
\text { is not positioned as } \\
\text { 'mild' or 'light'. }\end{array}$ & $\begin{array}{l}\text { If (1) and not } \\
(2)-(6)\end{array}$ \\
\hline & Light & $\begin{array}{l}\text { Does not contain } \\
\text { added flavors, is } \\
\text { positioned as 'mild' } \\
\text { or 'light'. }\end{array}$ & $\begin{array}{l}\text { If (2) and not } \\
(3)-(6)\end{array}$ \\
\hline
\end{tabular}

Codes: 1) regular or full (tobacco) flavor; 2) light or mild; 3) menthol or mint flavored; 4) clove flavored (kretek); 5) fruit or candy flavored; and 6) flavor capsule. to Table 1. A total of 526 participants $(46.8 \%$ of all participants) were categorized as flavored $(n=312)$ and non-flavored $(n=214)$ users at time of initiation. The remainder either indicated they did not have a preferred brand at the time of initiation or gave inconsistent answers which could not be coded.

\section{Sociodemographic characteristics}

We collected data on the participants' age, gender, ethnicity (Chinese, Malay, Indian, other), education level categorized as 'primary' (PSLE, no formal qualifications), 'secondary' (O/N level, NTC 3 or equivalent) 'pre-university' (A level, NTG 1-2 or equivalent, polytechnic or other diploma) or 'university and above', and monthly household income in SGD ( $\leq \$ 2000, \$ 2000-\$ 5999$, \$6000$\$ 9999, \geq \$ 10000$ ) (SGD: 1000 Singapore dollars about US\$750).

\section{Dependence level}

We assessed dependence level with frequency of smoking (daily, weekly, monthly, less than monthly) and Heaviness of Smoking Index (HSI). For participants who reported daily smoking, we calculated HSI score using two questions: 'on days that you smoke, how soon after you wake up do you have your first cigarette?' with responses 'after 60 minutes, within 31-60 minutes, within 6-30 minutes, within 5 minutes' and 'on days that you smoke, how many cigarettes do you typically smoke per day?' with responses ' 10 or fewer, 11-20, 21-30, 31 or more'. Each answer option was progressively assigned a score from 0 to $3^{32}$. Participants were then grouped into one of four dependence categories: 1) non-daily; 2) daily, low dependence (HSI score 0-1); 3) daily, moderate dependence (HSI score 2-4); and 4) daily, high dependence (HSI score 5-6).

\section{Smoking-related behaviors}

We collected data on intentions to quit (currently trying to quit, intends to quit in future, no intentions to quit, doesn't know), age of smoking initiation, and whether participants had ever tried using flavored cigarettes, capsule cigarettes and other tobacco or nicotine products. Participants who reported using capsule cigarettes at least some of the time were asked questions on how often they burst the capsule and when during smoking they preferred to burst the capsule. 


\section{Smoking-related perceptions}

For participants who reported using a regular brand, we collected data on their reasons for preferring this brand and perceptions of the brand's harmfulness compared to other brands. Participants who reported using flavored cigarettes at least some of the time were asked the question 'if flavored cigarettes were no longer available in Singapore, how do you think you would respond?' with the choice to select any of the options: 'I would try to quit smoking; I would switch to another cigarette; and I would try to obtain flavored cigarettes by other means'. We asked all participants to rate four different flavor variants of Marlboro, the most popular brand in Singapore, on a Likert scale in terms of overall appeal, packaging, taste, satisfaction, and harmfulness compared to other cigarettes. The variants included: 1 ) 'Red', a non-flavored regular cigarette; 2) 'Gold', a nonflavored light cigarette; 3) 'Menthol', a menthol-flavored cigarette; and 4) 'Splash Mega Purple', a mentholflavored cigarette with a fruit-flavored capsule.

\section{Statistical analysis}

Statistical analyses were conducted in two stages using $\mathrm{R}$ version 3.6.3. First, we used descriptive statistics and bivariate analyses to summarize our sample and compare the answers of flavored and non-flavored cigarette users. We used Pearson's chi-squared tests with Yates continuity correction and post hoc residuals with Bonferroni correction for categorical variables, and Student's t-tests for continuous variables. Second, we fitted a multivariate logistic regression model to identify correlates of flavored cigarette use. In the logistic regression model, a binary current flavored cigarette use variable (flavored vs non-flavored) was regressed on potential predictors including sociodemographics (age group, gender, ethnicity, education level, household income) and smokingrelated behaviors and perceptions (dependence level, intentions to quit, age of initiation, harm perception, reasons for brand preference). To determine the predictors to be included in the regression model, we first assessed each variable in a bivariate model by setting a liberal $p$ value $(p=0.20)$ and retained those variables that were significant at $p<0.20$ for the multivariate logistic regression analysis. The regression analysis yielded adjusted odds ratios (AOR) and 95\% confidence intervals (CI) to assess the relationships between the predictor variables and current flavored use.

\section{RESULTS}

\section{Sociodemographics and smoking-related behaviors}

Compared to the 2010 Singapore National Health Survey $^{33}$, a nationally representative survey of smokers in Singapore, our sample was similar in terms of age distribution but had a larger proportion of females (25.6\%) and Indians (13.1\%). Most of our study participants were educated to pre-university (41.3\%) or secondary (29.5\%) level, and most (49.2\%) had an intermediate monthly household income of $\$ 6000-$ \$9999 (Table 2).

Table 2. Sociodemographic characteristics of participants, shown for all participants as well as those categorized as non-flavored cigarette users or flavored cigarette users

\begin{tabular}{|c|c|c|c|}
\hline Characteristics & $\begin{array}{c}\text { All } \\
n(\%)\end{array}$ & $\begin{array}{c}\text { Non-flavored } \\
n(\%)\end{array}$ & $\begin{array}{c}\text { Flavored } \\
n(\%)\end{array}$ \\
\hline \multicolumn{4}{|l|}{ Age (years) } \\
\hline $20-29$ & $284(25.3)$ & $94(23.1)$ & $137(30.2)$ \\
\hline $30-39$ & $321(28.6)$ & $116(28.5)$ & $149(32.8)$ \\
\hline $40-49$ & $264(23.5)$ & $98(24.1)$ & $94(20.7)$ \\
\hline$\geq 50$ & $254(22.6)$ & 99 (24.3) & $74(16.3)$ \\
\hline \multicolumn{4}{|l|}{ Gender } \\
\hline Male & $833(74.4)$ & $336(83.0)$ & $288(63.6)$ \\
\hline Female & $286(25.6)$ & $69(17.0)$ & $164(36.4)$ \\
\hline \multicolumn{4}{|l|}{ Ethnicity } \\
\hline Chinese & $674(60.0)$ & 209 (51.4) & $281(61.9)$ \\
\hline Malay & $228(20.3)$ & $85(20.9)$ & $108(23.8)$ \\
\hline Indian & $147(13.1)$ & $83(20.4)$ & $36(7.9)$ \\
\hline Other & $74(6.6)$ & $30(7.4)$ & $29(6.4)$ \\
\hline \multicolumn{4}{|l|}{ Education level } \\
\hline Primary $^{\mathrm{a}}$ & $66(5.9)$ & $20(4.9)$ & $16(3.5)$ \\
\hline Secondary ${ }^{\mathrm{b}}$ & $331(29.5)$ & $127(31.2)$ & $118(26.0)$ \\
\hline Pre-universityc & $464(41.3)$ & $175(43.0)$ & $197(43.4)$ \\
\hline University and above & $262(23.3)$ & 85 (20.9) & $123(27.1)$ \\
\hline \multicolumn{4}{|l|}{$\begin{array}{l}\text { Average monthly } \\
\text { household income } \\
\text { (SGD) }\end{array}$} \\
\hline$\leq \$ 2000$ & 100 (8.9) & $59(15.9)$ & $58(13.9)$ \\
\hline$\$ 2000-\$ 5999$ & $172(15.3)$ & $216(58.1)$ & $212(51.0)$ \\
\hline$\$ 6000-\$ 9999$ & $552(49.2)$ & $57(15.3)$ & 85 (20.4) \\
\hline$\geq \$ 10000$ & $182(16.2)$ & $40(10.8)$ & $61(14.7)$ \\
\hline
\end{tabular}

SGD: 1000 Singapore dollars about US $\$ 750$. a No formal qualifications/primary, PSLE. b Secondary, O/N level or NTC 3 certificate or equivalent. c A level or NTC 1-2 certificate or equivalent, polytechnic diploma, other diploma and professional qualification. 
Most participants were daily smokers with a moderate dependence level $(48.0 \%)$ or low dependence level (28.0\%). Of all participants, $20.6 \%$ were non-daily smokers, $19.6 \%$ reported that they were attempting to quit and $19.8 \%$ were planning to quit in future, while $34.1 \%$ were unsure of their quit intentions, and $26.5 \%$ had no intention to quit.

\section{Use of flavored cigarettes and other tobacco products}

The vast majority $(85.2 \%)$ of participants reported they had ever used a flavored cigarette, while over half $(55.7 \%)$ reported they had ever used a capsule cigarette. Among participants who reported using capsule cigarettes at least some of the time, most (64.3\%) reported they 'always' burst the capsule, and most $(72.8 \%)$ preferred to burst the capsule prior to smoking the cigarette.

The majority of participants (78.2\%) indicated they had a regular brand or type of cigarette. For most of these participants $(52.7 \%)$, this regular brand was a flavored cigarette (34.6\% menthol non-capsule, $15.0 \%$ capsule, $2.0 \%$ kretek), for $25.8 \%$ it was a non-flavored regular cigarette, and for $21.5 \%$ it was a non-flavored light cigarette.

Besides cigarettes, other nicotine products participants most commonly reported having ever used were shisha (29.7\%), e-cigarettes (29.0\%), cigars $(28.8 \%)$, and roll your own tobacco $(28.3 \%)$. Flavored cigarette users were more likely than non-flavored users to have ever used e-cigarettes ( $37.2 \%$ vs $26.3 \%$, $\mathrm{p}<0.001)$ or shisha $(36.1 \%$ vs $28.5 \%, \mathrm{p}=0.021)$, while non-flavored users were more likely to have ever used cigars $(34.2 \%$ vs $26.7 \%, \mathrm{p}=0.002)$, roll your own tobacco $(32.9 \%$ vs $24.9 \%, \mathrm{p}=0.012)$, or pipe tobacco $(8.4 \%$ vs $4.6 \%, \mathrm{p}=0.036)$.

\section{Predictors of current flavored cigarette use}

Our regression analysis identified seven characteristics significantly associated with being a current flavored cigarette user: age, gender, ethnicity, dependence level, age of initiation, harm perception, and reasons for brand preference (Table 3).

Smokers who were older, age 40-49 years $(\mathrm{AOR}=0.63 ; 95 \% \mathrm{CI}: 0.41-0.98), \geq 50$ years $(\mathrm{AOR}=0.60 ; 95 \% \mathrm{CI}: 0.37-0.97)$ and of Indian ethnicity (AOR=0.39; 95\% CI: 0.24-0.52) were less likely to use flavored cigarettes, while females were more likely than males to use flavored cigarettes $(\mathrm{AOR}=2.53$; 95\% CI: 1.77-3.63). Daily smokers who reported a moderate $(\mathrm{AOR}=0.57$; 95\% CI: $0.36-$ $0.88)$ or high dependence level $(\mathrm{AOR}=0.34 ; 95 \%$ CI: 0.13-0.86) were less likely to use flavored cigarettes

Table 3. Results of multivariate logistic regression assessing correlates of flavored cigarette use

\begin{tabular}{|c|c|c|}
\hline Variable & AOR $(95 \% \mathrm{CI})$ & $p$ \\
\hline \multicolumn{3}{|l|}{ Age } \\
\hline $20-29$ & Ref. & - \\
\hline $30-39$ & $0.98(0.65-1.46)$ & 0.90 \\
\hline $40-49$ & $0.63(0.41-0.98)$ & $0.04^{*}$ \\
\hline$\geq 50$ & $0.60(0.37-0.97)$ & $0.04^{*}$ \\
\hline \multicolumn{3}{|l|}{ Gender } \\
\hline Male & Ref. & - \\
\hline Female & $2.53(1.77-3.63)$ & $<0.01^{*}$ \\
\hline \multicolumn{3}{|l|}{ Ethnicity } \\
\hline Chinese & Ref. & - \\
\hline Malay & $0.94(0.63-1.39)$ & 0.74 \\
\hline Indian & $0.39(0.24-0.52)$ & $<0.01^{*}$ \\
\hline Others & $0.64(0.34-1.19)$ & 0.16 \\
\hline \multicolumn{3}{|l|}{ Education level } \\
\hline Primary & $1.10(0.47-2.52)$ & 0.83 \\
\hline Secondary & $1.06(0.67-1.68)$ & 0.79 \\
\hline Pre-university & $1.02(0.69-1.51)$ & 0.92 \\
\hline University and above & Ref. & - \\
\hline \multicolumn{3}{|l|}{ Dependence level } \\
\hline Non-daily & Ref. & - \\
\hline Daily, low dependence & $0.67(0.42-1.07)$ & 0.09 \\
\hline Daily, moderate dependence & $0.57(0.36-0.88)$ & $0.01^{*}$ \\
\hline Daily, high dependence & $0.34(0.13-0.86)$ & $0.02^{*}$ \\
\hline \multicolumn{3}{|l|}{ Age of initiation (years) } \\
\hline$\leq 15$ & Ref. & - \\
\hline $16-20$ & $1.72(1.23-2.41)$ & $<0.01^{*}$ \\
\hline$\geq 21$ & $2.19(1.33-3.66)$ & $<0.01^{*}$ \\
\hline \multicolumn{3}{|l|}{ Harm Perception } \\
\hline Less harmful & Ref. & - \\
\hline Equally/more harmful & $1.88(1.12-3.16)$ & $0.02^{*}$ \\
\hline \multicolumn{3}{|l|}{ Reason for brand preference } \\
\hline It tastes better & $1.30(0.94-1.79)$ & 0.11 \\
\hline It smells better & 1.27(0.84-1.93) & 0.26 \\
\hline It provides a stronger kick & $0.29(0.19-0.45)$ & $<0.01^{*}$ \\
\hline It is smoother on my airways & $1.37(1.00-1.88)$ & 0.05 \\
\hline It is cheaper & $1.91(1.34-2.74)$ & $<0.01^{*}$ \\
\hline I started smoking that brand & $0.82(0.55-1.22)$ & 0.33 \\
\hline
\end{tabular}

*Statistically significant results $(\mathrm{p}<0.05)$. AOR: adjusted odds ratio. $\mathrm{Cl}$ : confidence interval. 
compared to non-daily smokers. Those who started smoking at age 16 years or later were more likely to use flavored cigarettes compared to those who started at age $\leq 15$ years: $16-20$ years $(\mathrm{AOR}=1.72$; 95\% CI: $1.23-2.41)$; $\geq 21$ years $(\mathrm{AOR}=2.19 ; 95 \% \mathrm{CI}$ : 1.33-3.66).

Finally, flavored cigarette users were more likely to perceive their brand as equally or more harmful than other brands (AOR=1.88; 95\% CI: $1.12-3.16)$, and to prefer their brand because 'it is cheaper' $(\mathrm{AOR}=1.91$; 95\% CI: 1.34-2.74). Preferring a brand because it provides a stronger kick' was associated with being a non-flavored cigarette user $(\mathrm{AOR}=0.29 ; 95 \%$ CI: 0.19-0.45).

\section{Smoking-related perceptions}

Among participants who reported having a regular brand, most ( $88.4 \%$ ) perceived their brand as equally harmful to other brands. A further $10.2 \%$ perceived their brand as less harmful; these participants were more likely to be smokers of non-flavored light cigarettes compared to flavored or regular nonflavored cigarettes $(16.8 \%$ vs $7.7 \%$ and $7.2 \%$; $p<0.006$, chi-squared with adjusted residuals).

Table 4 displays the results of chi-squared tests to assess associations between perceptions of different Marlboro variants and flavored cigarette use among adult smokers. Brand recognition was high, with virtually all (99.7\%) participants reporting that they had heard of the Marlboro brand. Compared to nonflavored cigarette users, flavored users were more likely to perceive the non-flavored variants (regular and light) less favorably and the flavored variants (non-capsule and capsule) more favorably in terms of look/packaging, taste, satisfaction, and overall appeal. Harm perceptions of the different variants were similar between flavored and non-flavored cigarette users.

Participants who reported using flavored cigarettes 'some of the time', 'most of the time' or 'always' were asked how they would respond if flavored cigarettes were no longer available in Singapore. In all, 67.7\% reported they would switch to another cigarette, $32.0 \%$ would try to quit, and $18.3 \%$ would try to obtain them by other means.

\section{Smoking initiation}

The average age of smoking initiation among participants was 17 years (median 17 years, mean 16.9 years). The vast majority ( $86.4 \%$ ) had started smoking by the age of 20 years and virtually all $(97.5 \%)$ by 25 years. Less than half $(48.3 \%)$ of participants retrospectively recalled having a regular brand at initiation. This low proportion may be due to low levels of recall or low levels of brand loyalty at the smoking initiation stage.

Among participants who reported having a regular brand at initiation, the majority $(57.5 \%)$ initiated with a flavored cigarette. Female participants were, compared with males, more likely to have started smoking with a flavored cigarette $(73.4 \%$ vs $47.0 \%$; $\mathrm{p}<0.001$, chi-squared). Those who started with a flavored cigarette were, compared to those who started with a non-flavored cigarette, more likely to report they preferred their starting brand because it was 'smoother on my airways' (35.6\% vs $16.8 \%$; $\mathrm{p}<0.001$, chi-squared), 'more interesting' ( $8.0 \% \mathrm{vs}$ $2.3 \% ; \mathrm{p}=0.01$, chi-squared), 'smelled better' $(18.3 \%$ vs $10.3 \%$; $\mathrm{p}=0.017$, chi-squared) and 'tasted better' ( $55.1 \%$ vs $45.3 \%$; $\mathrm{p}=0.034$, chi-squared). Those who started with a non-flavored cigarette were more likely to report they preferred their starting brand because 'it provided a stronger kick' ( $25.2 \%$ vs $11.5 \%$; $\mathrm{p}<0.001$, chi-squared).

Across different age groups, younger participants were more likely than older participants to have initiated smoking with a flavored cigarette: $63.9 \%$ of those aged 20-29 years, $58.1 \%$ of those aged $30-39$ years, and $52.3 \%$ of those aged $40-49$ years initiated with flavored cigarettes, compared to $39.7 \%$ of participants aged $\geq 50$ years $(\mathrm{p}<0.004$, chisquared with adjusted residuals). After categorizing participants by the decade in which they started smoking, we found that those who started smoking in more recent decades were more likely to have initiated with a flavored cigarette; $82.6 \%$ of those who started smoking in the 2010 s started with a flavored cigarette, compared to $68.6 \%$ in the 2000 s, $55.8 \%$ in the $1990 \mathrm{~s}$, and $35.9 \%$ in $1960-1980$.

Of those who initiated with a flavored cigarette, $76.0 \%$ were still using a flavored cigarette at the time of survey. Of those who initiated with a non-flavored cigarette, $74.0 \%$ were still using a non-flavored cigarette at the time of survey. Thus, for both flavored and non-flavored cigarettes, the 'switching out' rate from initiation to the time of survey was around 1 in 4 . 
Table 4. Perceptions of different flavor variants as reported by non-flavored (NF) and flavored (F) cigarette users

\begin{tabular}{|c|c|c|c|c|c|c|c|c|}
\hline \multirow[t]{2}{*}{ Response } & \multicolumn{2}{|c|}{$\begin{array}{c}\text { Red } \\
\text { (non-flavored, regular) }\end{array}$} & \multicolumn{2}{|c|}{$\begin{array}{c}\text { Gold } \\
\text { (non-flavored, light) }\end{array}$} & \multicolumn{2}{|c|}{$\begin{array}{c}\text { Menthol } \\
\text { (non-capsule) }\end{array}$} & \multicolumn{2}{|c|}{$\begin{array}{l}\text { Splash mega purple } \\
\text { (capsule) }\end{array}$} \\
\hline & NF, $n(\%)$ & $F, n(\%)$ & $N F, n(\%)$ & $F, n(\%)$ & $N F, n(\%)$ & $F, n(\%)$ & $N F, n(\%)$ & $F, n(\%)$ \\
\hline \multicolumn{9}{|l|}{$\begin{array}{l}\text { 'I like the look of } \\
\text { the packaging and } \\
\text { cigarette' }\end{array}$} \\
\hline Strongly agree & $52(12.8)^{* *}$ & $33(7.3)$ & $82(20.1)$ & $59(13.1)$ & $51(12.5)$ & $77(17.0)$ & $78(19.2)$ & $111(24.6)$ \\
\hline Somewhat agree & $213(52.3)$ & $218(48.0)$ & 207 (50.9) & 235 (52.0) & $176(43.2)$ & $245(54.1)^{* *}$ & $152(37.3)$ & $219(48.5)^{* *}$ \\
\hline Somewhat disagree & $92(22.6)$ & $140(30.8)^{* * *}$ & $84(20.6)$ & $110(24.3)$ & $123(30.2)^{* * *}$ & $94(20.8)$ & $99(24.3)^{* * *}$ & $77(17.0)$ \\
\hline Strongly disagree & $50(12.3)$ & $63(13.9)$ & $34(8.4)$ & $48(10.6)$ & $57(14.0)^{* *}$ & $37(8.2)$ & $78(19.2)^{* * *}$ & $45(10.0)$ \\
\hline \multicolumn{9}{|l|}{$\begin{array}{l}\text { 'This looks like the } \\
\text { kind of cigarette I } \\
\text { would smoke' }\end{array}$} \\
\hline Strongly agree & $62(15.2)^{* * *}$ & $16(3.5)$ & $95(23.3)^{* * *}$ & $20(4.4)$ & $24(5.9)$ & $96(21.2)^{* * *}$ & $26(6.4)$ & $93(20.6)^{* * *}$ \\
\hline Somewhat agree & $195(47.9)^{* * *}$ & $108(23.8)$ & $160(39.3)$ & $161(35.6)$ & $112(27.5)$ & $256(56.5)^{* * *}$ & 96 (23.6) & $205(45.4)^{* * *}$ \\
\hline Somewhat disagree & $85(20.9)$ & $164(36.1)^{* * *}$ & $108(26.5)$ & $168(37.2)^{* * *}$ & $170(41.8)^{* * *}$ & $67(14.8)$ & $152(37.3)^{* * *}$ & $95(21.0)$ \\
\hline Strongly disagree & $65(16.0)$ & $166(36.6)^{* * *}$ & $44(10.8)$ & $103(22.8)^{* * *}$ & $101(24.8)^{* * *}$ & $34(7.5)$ & $133(32.7)^{* * *}$ & 59 (13.1) \\
\hline \multicolumn{9}{|l|}{$\begin{array}{l}\text { 'This cigarette looks } \\
\text { like it would have a } \\
\text { nice taste' }\end{array}$} \\
\hline Strongly agree & $51(12.5)^{* * *}$ & $17(3.7)$ & $60(14.7)^{* * *}$ & $19(4.2)$ & $24(5.9)$ & $78(17.2)^{* * *}$ & $34(8.4)$ & $91(20.1)^{* * *}$ \\
\hline Somewhat agree & $181(44.5)^{* * *}$ & 105 (23.1) & $176(43.2)$ & 159 (35.2) & 139 (34.2) & $239(52.8)^{* * *}$ & 134 (32.9) & $219(48.5)^{* * *}$ \\
\hline Somewhat disagree & 112 (27.5) & $189(41.6)^{* * *}$ & 118 (29.0) & $174(38.5)^{* * *}$ & $153(37.6)^{* * *}$ & 99 (21.9) & $130(31.9)^{* * *}$ & $90(19.9)$ \\
\hline Strongly disagree & $63(15.5)$ & $143(31.5)^{* * *}$ & $53(13.0)$ & $100(22.1)^{* * *}$ & $91(22.4)^{* * *}$ & $37(8.2)$ & $109(26.8)^{* * *}$ & $52(11.5)$ \\
\hline \multicolumn{9}{|l|}{$\begin{array}{l}\text { 'This cigarette looks } \\
\text { like it would be } \\
\text { satisfying' }\end{array}$} \\
\hline Strongly agree & $54(13.3)^{* * *}$ & $20(4.4)$ & $62(15.2)^{* * *}$ & $16(3.5)$ & $21(5.2)$ & $70(15.5)^{* * *}$ & $26(6.4)$ & $70(15.5)^{* * *}$ \\
\hline Somewhat agree & $195(47.9)^{* * *}$ & $137(30.2)$ & $165(40.5)$ & $161(35.6)$ & $131(32.2)$ & $239(52.8)^{* * *}$ & 119 (29.2) & $221(48.9)^{* * *}$ \\
\hline Somewhat disagree & $99(24.3)$ & $170(37.4)^{* * *}$ & $120(29.5)$ & $176(38.9)^{* * *}$ & $158(38.8)^{* * *}$ & 105 (23.2) & $144(35.4)^{* * *}$ & 101 (22.3) \\
\hline Strongly disagree & $59(14.5)$ & $127(28.0)^{* * *}$ & $60(14.7)$ & $99(21.9)^{* * *}$ & $97(23.8)^{* * *}$ & $39(8.6)$ & $118(29.0)^{* * *}$ & $60(13.3)$ \\
\hline \multicolumn{9}{|l|}{$\begin{array}{l}\text { 'This cigarette looks } \\
\text { less harmful than } \\
\text { other cigarettes' }\end{array}$} \\
\hline Strongly agree & $8(2.0)$ & $14(3.1)$ & $18(4.4)$ & $14(3.1)$ & $8(2.0)$ & $20(4.4)$ & $10(2.5)$ & $20(4.4)$ \\
\hline Somewhat agree & $50(12.3)^{* * *}$ & $28(6.2)$ & $90(22.1)$ & $85(18.8)$ & $53(13.0)$ & $78(17.2)$ & $55(13.5)$ & 69 (15.3) \\
\hline Somewhat disagree & 134 (32.9) & 149 (32.8) & $118(29.0)$ & 149 (33.0) & $153(37.6)$ & 157 (34.7) & 138 (33.9) & $164(36.3)$ \\
\hline Strongly disagree & 215 (52.8) & $263(57.9)$ & $181(44.5)$ & $204(45.1)$ & $193(47.4)$ & $198(43.7)$ & $204(50.1)$ & $199(44.0)$ \\
\hline
\end{tabular}

Significant differences are indicated as: ${ }^{*} p<0.05,{ }^{* *} p<0.01$ or ${ }^{* * *} \mathrm{p}<0.001$; chi-squared test with Bonferroni correction and adjusted residuals post hoc.

\section{DISCUSSION}

This study is, to our knowledge, the first to identify correlates of flavored cigarette use in a multi-ethnic Asian population. In our sample of Singapore smokers, the prevalence of flavored cigarette use was high with $85.2 \%$ of respondents reporting ever use and $52.7 \%$ of respondents with a regular brand reporting current use of flavored cigarettes. This estimate is higher than the prevalence of flavored cigarette use reported among smokers in studies from the United States ${ }^{28}$ and the European Union ${ }^{26}$. It is also consistent with market data which show that Singapore's flavored cigarette market share is higher than that of most other countries $^{25}$. Use of flavor capsule cigarettes was also 
prevalent in our sample, with $55.7 \%$ of respondents reporting ever use and $15.0 \%$ of respondents with a regular brand reporting current use.

We found that current use of flavored cigarettes in Singapore smokers was correlated with being female or of non-Indian (Chinese or Malay) ethnicity. Female smokers were also more likely to have initiated with flavored cigarettes. This is consistent with studies from the European Union ${ }^{26,27}$, the United States ${ }^{28}$, and Chile ${ }^{30}$, which found higher rates of flavored tobacco use in females, and a study from the United States which shows a higher prevalence of flavored tobacco use in certain ethnic groups (African and Hispanic $)^{28}$. These differences may be a result of the tobacco industry's targeted marketing of flavored cigarettes $^{7,8,14}$, which has targeted females and specific ethnic groups in Singapore ${ }^{1}$, as well as variations in the taste and other sensory preferences between different genders or ethnic groups ${ }^{14,34}$. Our findings also suggest that, in the Asian context, regulations on tobacco flavors may be especially effective in deterring smoking among females and people of Malay or Chinese ethnicity, and that smoking prevention efforts may need to adopt a more gender-sensitive or culturally sensitive approach.

Consistent with findings from the European Union $^{26,27}$, the United States ${ }^{28}$, and Chile ${ }^{30}$, we also found that, in Singapore, current use of flavored cigarettes is correlated with being younger in age (20-39 years), having initiated at a later age, and having a lower nicotine dependence level. In addition, smokers who were younger in age or who initiated smoking more recently were more likely to have started smoking with a flavored cigarette. Put together, initiation with flavored cigarettes seems to have become more prevalent over time among our survey participants. This could be a reflection of market trends which show that Singapore's menthol (non-capsule) cigarette market started growing in the 1980 s and $1990 \mathrm{~s}^{1}$, stabilizing in the late 2000 s to its current share of around $48 \%{ }^{25}$. This stable trend, together with our observation of the low switching rates between flavored and non-flavored cigarettes, also suggests that the majority of smokers in our sample who initiated smoking with flavored cigarettes continued to use flavored cigarettes in later life.

Flavored cigarettes, especially those with menthol flavor, encourage smoking initiation as they mask the harshness of tobacco smoke $\mathrm{s}^{5-10}$, are sold in novelty flavors that appeal to young people ${ }^{17-23}$, and may be perceived as less harmful ${ }^{13-16}$. Among our Singapore respondents, flavored cigarette users were more likely to prefer their brand for the cheaper price and, at initiation, for the novelty, smell, taste, and smoothness on the airways. While they did not rate flavored cigarettes as less harmful than other brands, it is worth noting that 'smoothness' and 'mild taste' may be indirectly associated with a perception of reduced harm ${ }^{35}$, which may have influenced respondents' perceptions of harmfulness at the smoking initiation stage. In most flavored cigarettes, smoothness and mild taste are elicited by menthol which acts as a local anaesthetic in the throat ${ }^{16}$.

Finally, among respondents who regularly used flavored cigarettes, almost a third (32.0\%) reported they would try to quit if flavored cigarettes were no longer available in Singapore. Based on this result, we would expect a substantial increase in quit attempts following the implementation of a tobacco flavors ban in Singapore. However, the original intentions reported prior to a flavors ban may not reflect the observed behaviors following its implementation. Prior to implementation of a tobacco flavors ban in Ontario, Canada, 15\% had reported that they would quit, whereas after the ban, almost twice that proportion (29\%) had attempted to quit ${ }^{3}$. The impact on cessation rate is also likely to vary depending on the breadth of the flavors ban and the size of the pre-existing flavors market. In the European Union, where smoking cessation rates were not significantly impacted by a flavors ban $^{36}$, tobacco companies had launched new products such as flavored inserts and cigarillos to discourage quitting among flavored cigarette users ${ }^{37,38}$. Additionally, the pre-existing market share of flavored cigarettes in the European countries was, compared to Singapore's, far smaller, ranging from $0.4 \%-12.4 \%{ }^{26}$, making significant differences in quitting rates harder to detect.

\section{Limitations}

Our study findings should be carefully interpreted with the limitations of the study. Although our study sample was similar to the 2010 National Health Survey in terms of sociodemographic characteristics ${ }^{33}$, our sample is not representative of the Singapore population and, as such, we were unable to obtain 
a more reliable estimate of flavored cigarette use in Singapore. In addition, causal relationships cannot be determined due to the nature of a cross-sectional study design. To address these limitations, future research would utilize a longitudinal cohort design with a rigorous representative sampling procedure. Our sample included current smokers aged $\geq 21$ years; hence our results cannot provide detailed insight into the role of flavors in smoking initiation. Finally, the study relied upon self-reported data from participants who agreed to be re-contacted for follow-up research, collected online or by post; door to door surveys were not possible due to the COVID-19 social distancing measures. This may influence the results as a result of selection bias, social desirability bias, or issues with the retrospective recall of answers related to smoking initiation. Despite these limitations, the study provides important insights into the characteristics and correlates of flavored cigarette use in a multiethnic, urban Asian setting.

\section{CONCLUSIONS}

In Singapore, flavored cigarette use is associated with being female and having a later initiation age, while non-flavored cigarette use is associated with Indian ethnicity, older age, and having a moderate or high nicotine dependence level.

\section{REFERENCES}

1. van der Eijk Y, Lee JK, M Ling P. How Menthol Is Key to the Tobacco Industry's Strategy of Recruiting and Retaining Young Smokers in Singapore. J Adolesc Health. 2019;64(3):347-354. doi:10.1016/j.jadohealth.2018.09.001

2. Thrasher JF, Islam F, Barnoya J, Mejia R, Valenzuela MT, Chaloupka FJ. Market share for flavour capsule cigarettes is quickly growing, especially in Latin America. Tob Control. 2017;26(4):468-470. doi:10.1136/tobaccocontrol-2016-053030

3. Cadham CJ, Sanchez-Romero LM, Fleischer NL, et al. The actual and anticipated effects of a menthol cigarette ban: a scoping review. BMC Public Health. 2020;20(1):1055. doi:10.1186/s12889-020-09055-z

4. Erinoso O, Clegg Smith K, Iacobelli M, Saraf S, Welding $\mathrm{K}$, Cohen JE. Global review of tobacco product flavour policies. Tob Control. Published online May 15, 2020. doi:10.1136/tobaccocontrol-2019-055454

5. Kowitt SD, Meernik C, Baker HM, Osman A, Huang LL, Goldstein AO. Perceptions and Experiences with Flavored Non-Menthol Tobacco Products: A Systematic Review of Qualitative Studies. Int J Environ Res Public Health. 2017;14(4):338. doi:10.3390/ijerph14040338
6. Carpenter CM, Wayne GF, Pauly JL, Koh HK, Connolly GN. New cigarette brands with flavors that appeal to youth: tobacco marketing strategies. Health Aff. 2005;24(6):1601-1610. doi:10.1377/hlthaff.24.6.1601

7. Connolly GN, Behm I, Osaki Y, Wayne GF. The impact of menthol cigarettes on smoking initiation among nonsmoking young females in Japan. Int J Environ Res Public Health. 2011;8(1):1-14. doi:10.3390/ijerph8010001

8. Klausner K. Menthol cigarettes and smoking initiation: a tobacco industry perspective. Tob Control. 2011;20(Suppl 2):ii12-ii19. doi:10.1136/tc.2010.041954

9. Kreslake JM, Wayne GF, Alpert HR, Koh HK, Connolly GN. Tobacco industry control of menthol in cigarettes and targeting of adolescents and young adults. Am J Public Health. 2008;98(9):1685-1692. doi:10.2105/AJPH.2007.125542

10. Nonnemaker J, Hersey J, Homsi G, Busey A, Allen J, Vallone D. Initiation with menthol cigarettes and youth smoking uptake. Addiction. 2013;108(1):171-178. doi:10.1111/j.1360-0443.2012.04045.x

11. Anderson SJ. Menthol cigarettes and smoking cessation behaviour: a review of tobacco industry documents. Tob Control. 2011;20(Suppl 2):ii49-ii56. doi:10.1136/tc.2010.041947

12. Ferris Wayne G, Connolly GN. Application, function, and effects of menthol in cigarettes: a survey of tobacco industry documents. Nicotine Tob Res. 2004;6(Suppl 1):S43-S54. doi:10.1080/14622203310001649513

13. Huang LL, Baker HM, Meernik C, Ranney LM, Richardson A, Goldstein AO. Impact of nonmenthol flavours in tobacco products on perceptions and use among youth, young adults and adults: a systematic review. Tob Control. 2017;26(6):709-719. doi:10.1136/tobaccocontrol-2016-053196

14. Anderson SJ. Marketing of menthol cigarettes and consumer perceptions: a review of tobacco industry documents. Tob Control. 2011;20(Suppl 2):ii20-ii28. doi:10.1136/tc.2010.041939

15. Kreslake JM, Wayne GF, Connolly GN. The menthol smoker: tobacco industry research on consumer sensory perception of menthol cigarettes and its role in smoking behavior. Nicotine Tob Res. 2008;10(4):705-715. doi:10.1080/14622200801979134

16. Advisory note: banning menthol in tobacco products: WHO study Group on Tobacco Product Regulation (TobReg). World Health Organization; 2016. Accessed March 24, 2021. https://apps.who.int/iris/bitstream/ handle/10665/205928/9789241510332_eng.pdf

17. Abad-Vivero EN, Thrasher JF, Arillo-Santillán E, et al. Recall, appeal and willingness to try cigarettes with flavour capsules: assessing the impact of a tobacco product innovation among early adolescents. Tob Control. 2016;25(e2):e113-e119. doi:10.1136/tobaccocontrol-2015-052805

18. Brown J, Zhu M, Moran M, Hoe C, Frejas F, Cohen JE. 'It has candy. You need to press on it': young adults' perceptions of flavoured cigarettes in the Philippines. 
Tob Control. 2020. Published online May 23, 2020. doi:10.1136/tobaccocontrol-2019-055524

19. Menthol Capsules in Cigarette Filters - Increasing the Attractiveness of a Harmful Product. German Cancer Research Center; 2012. Red Series Tobacco Prevention and Tobacco Control. Vol. 17. Accessed March 24, 2021. https://www.dkfz.de/de/tabakkontrolle/download/ Publikationen/RoteReihe/Band_17_Menthol_Capsules_ in_Cigarette_Filters_en.pdf

20. Hoek J, Gendall P, Eckert C, Louviere J, Blank ML, Thrasher JF. Young adult susceptible non-smokers' and smokers' responses to capsule cigarettes. Tob Control. 2019;28(5):498505. doi:10.1136/tobaccocontrol-2018-054470

21. Moodie C, Ford A, Dobbie F, Thrasher JF, McKell J, Purves R. The Power of Product Innovation: Smokers' Perceptions of Capsule Cigarettes. Nicotine Tob Res. 2018;20(9):1157-1160. doi:10.1093/ntr/ntx195

22. Moodie C, Thrasher JF, Cho YJ, Barnoya J, Chaloupka FJ. Flavour capsule cigarettes continue to experience strong global growth. Tob Control. 2019;28(5):595-596. doi:10.1136/tobaccocontrol-2018-054711

23. Thrasher JF, Abad-Vivero EN, Moodie C, et al. Cigarette brands with flavour capsules in the filter: trends in use and brand perceptions among smokers in the USA, Mexico and Australia, 2012-2014. Tob Control. 2016;25(3):275283. doi:10.1136/tobaccocontrol-2014-052064

24. Amul GGH, Pang PT. Progress in Tobacco Control in Singapore: Lessons and Challenges in the Implementation of the Framework Convention on Tobacco Control. Asia \& the Pacific Policy Studies. 2018;5(1):102-121. doi:10.1002/app5.222

25. Passport: Global Market Information Database. Euromonitor International; 2018. Accessed March 24, 2021. https://go.euromonitor.com/passport.html

26. Zatoński M, Herbeć A, Zatoński W, et al. Characterising smokers of menthol and flavoured cigarettes, their attitudes towards tobacco regulation, and the anticipated impact of the Tobacco Products Directive on their smoking and quitting behaviours: The EUREST-PLUS ITC Europe Surveys. Tob Induc Dis. 2018;16(Suppl 2):113. doi:10.18332/tid/96294

27. Kaleta D, Usidame B, Szosland-Fałtyn A, MakowiecDąbrowska T. Use of flavoured cigarettes in Poland: data from the global adult tobacco survey (2009-2010). BMC Public Health. 2014;14(1):127. doi:10.1186/1471-2458-14-127

28. Smith DM, Bansal-Travers M, Huang J, Barker D, Hyland AJ, Chaloupka F. Association between use of flavoured tobacco products and quit behaviours: findings from a cross-sectional survey of US adult tobacco users. Tob Control. 2016;25(Suppl 2):ii73-ii80. doi:10.1136/tobaccocontrol-2016-053313

29. Villanti AC, Richardson A, Vallone DM, Rath JM. Flavored tobacco product use among U.S. young adults. Am J Prev Med. 2013;44(4):388-391. doi:10.1016/j.amepre.2012.11.031
30. Paraje G, Araya D, Drope J. The association between flavor capsule cigarette use and sociodemographic variables: Evidence from Chile. PLoS One. 2019;14(10):e0224217. doi:10.1371/journal.pone.0224217

31. National Health Interview Survey: Glossary. Centers for Disease Control and Prevention; 2020. Accessed December 9, 2020. https://www.cdc.gov/nchs/nhis/ tobacco/tobacco_glossary.htm\#: :text=Smoking $\% 20$ status $\% 3 \mathrm{~A} \% 20 \mathrm{~A} \% 20$ recoded $\% 20$ variablesmoked $\% 2 \mathrm{C} \% 20$ and $\% 20$ smoking\%20status\%20unknown

32. Heatherton TF, Kozlowski LT, Frecker RC, Rickert W, Robinson J. Measuring the heaviness of smoking: using selfreported time to the first cigarette of the day and number of cigarettes smoked per day. Br J Addict. 1989;84(7):791800. doi:10.1111/j.1360-0443.1989.tb03059.x

33. Chua LAV. National Health Survey 2010. Statistics Singapore Newsletter. Singapore Ministry of Health; 2010. Accessed March 24, 2021. https://www.singstat. gov.sg/-/media/files/publications/society/ssnmar10pg25-27.pdf

34. Moodie C, Ford A, Mackintosh A, Purves R. Are all cigarettes just the same? Female's perceptions of slim, coloured, aromatized and capsule cigarettes. Health Educ Res. 2015;30(1):1-12. doi:10.1093/her/cyu063

35. Elton-Marshall T, Fong GT, Zanna MP, et al. Beliefs about the relative harm of "light" and "low tar" cigarettes: findings from the International Tobacco Control (ITC) China Survey. Tob Control. 2010;19(Suppl-2):i54-i62. doi:10.1136/tc.2008.029025

36. Zatoński M, Herbeć A, Zatoński W, et al. Cessation behaviours among smokers of menthol and flavoured cigarettes following the implementation of the EU Tobacco Products Directive: findings from the EUREST-PLUS ITC Europe Surveys. Eur J Public Health. 2020;30(Suppl 3):iii34-iii37. doi:10.1093/eurpub/ckaa050

37. Branston JR, Hiscock R, Silver K, Arnott D, Gilmore AB. Cigarette-like cigarillo introduced to bypass taxation, standardised packaging, minimum pack sizes, and menthol ban in the UK. Tob Control. 2020. Published online August 26, 2020. doi:10.1136/tobaccocontrol-2020-055700

38. Hiscock R, Silver K, Zatoński M, Gilmore AB. Tobacco industry tactics to circumvent and undermine the menthol cigarette ban in the UK. Tob Control. 2020;29(e1):e138-e142. doi:10.1136/tobaccocontrol-2020-055769

\section{ACKNOWLEDGEMENTS}

We thank the students of Community Health Project Group 4, especially group leaders Xavier Ho and Desiree Tay, and the Singapore Population Health Studies team, especially Linda Tan and Shumian Yeo, for their help with earlier parts of the project. We also thank Lit Fai Chan and Kee Seng Chia for their helpful feedback on our survey questionnaire and an earlier draft of this manuscript. 


\section{CONFLICTS OF INTEREST}

The authors have each completed and submitted an ICMJE form for disclosure of potential conflicts of interest. The authors declare that they have no competing interests, financial or otherwise, related to the current work. Y. van der Eijk reports a grant (R-608-000-262-223) from the Singapore Ministry of Health.

FUNDING

This work was supported by the Singapore Ministry of Health (R-608000-262-223).

\section{ETHICAL APPROVAL AND INFORMED CONSENT}

The survey questionnaire, recruitment materials, data collection and data security plan were reviewed and approved by the National University of Singapore's Institutional Review Board (NUS-IRB reference S-19-338). All participants reviewed a participant information sheet and provided informed consent either electronically or via hard copy prior to completing the survey.

\section{AUTHORS' CONTRIBUTIONS}

YVDE: study conceptualization, data analysis, and writing. XYN: data analysis. JKL: study conceptualization, data analysis, and writing.

PROVENANCE AND PEER REVIEW

Not commissioned; externally peer reviewed. 